\title{
Mülkiyet Yapısının Finansman Kararları Üzerindeki Etkisi
}

Mesut DOĞAN*

\section{ÖZET}

Büyük hissedarlar, firma içi denetim gücüne ve güdüye sahip olmalarından dolayı kendi çıkarlarını maksimize etmeye çalışabilirler. Buna karşın büyük hissedarlara sahip firmalar devamlılıklarını korumaktadırlar ve büyük hissedarlar işletme içerisinde neler olduğunu gözlemleyip izleme ve müdahale etme olanağına sahiptir. Bu çalışmanın amacı mülkiyet yapısının finansman kararları üzerindeki etkisini tespit etmektir. Araştırmada 2005-2012 yılları arasında Borsa İstanbul (BIST) imalat sanayide hisse senetleri işlem gören 136 firmanın verilerinden yararlanılmıştır. Araştırmada kullanılan veriler dengeli panel veri özelliği taşımaktadır. Ampirik analizlerde White periyot standart hataları ve kovaryans katsayısı yönteminden yararlanılmıştır. Yapılan analizler sonucunda en büyük ortağın sermaye payı, firma büyüklüğ̈̈ ve varlık karlıliğı BIST imalat sanayi firmalarının finansman kararları üzerinde etkili olduğu tespit edilmiştir.

Anahtar Kelimeler: Mülkiyet Yapısı, Finansman Kararları, Sermaye Yapısı.

JEL Sinıflandırması: G30, G32.

\section{The Impact of Ownership Structure on Financing Decisions}

\section{ABSTRACT}

Because of the large shareholders have a motive power and internal audit can try to maximize their own interests. In contrast, firms with major shareholders retain their continuity and major shareholders have the opportunity to intervene watch and monitor what is happening in the company. The aim of this study is to determine the impact of ownership structure on financing decisions. The study made use of data of 136 firms continuously active in BIST manufacturing industry between 2005 and 2012. In the study, panel data analysis was used. White period standard errors and covariance method have been employed in empirical analyzes. As a result of analyses, ownership structure, firm size, major shareholders have been found to be effective in the BIST firm financing decisions.

Keywords: Ownership Structure, Financing Decisions, Capital Structure.

Jel Classification: G30, G32.

\footnotetext{
Dr. Mesut DOĞAN, Afyon Kocatepe Üniversitesi, Bayat MYO, İsletme Bölümü, mesutdogan@aku.edu.tr.
} 


\section{GíRiş}

Firmaların finansman politikası olarak vermesi gereken en önemli kararlardan biri firmanın sermaye yapısının nasıl olması gerektiğidir. Bir firmanın sermaye yapısı, yabancı kaynaklar ve öz sermayeden oluşan bilançonun pasif kısmıdır. Bu açıdan bilançonun pasif kısmında ne kadar yabancı kaynak ve ne kadar öz kaynak kullanması gerektiği ve bu kararların firma değeri üzerinde yaratacağı etkiler firmalar için son derece önemli olmaktadır (Ercan ve Ban 2005: 227). Bununla birlikte iflas ve temsil maliyetleri işletmelerin borçlanmalarını etkilemektedir. Finansal sıkıntı maliyetleri, işletmelerin likidite sorunları sebebiyle karşılaşabilecekleri ve iflas süreciyle sonuçlanabilecek durumların firmaya olan maliyetleridir. Temsil maliyetleri ise esas olarak firmanın hissedarları ile yöneticileri arasında oluşacak çıkar çatışmalarından kaynaklanan maliyetleri ifade etmektedir. Yöneticiler riski düşürmek güdüsüyle hareket ederken, hisse senedi sahipleri riskin artıp artmamasından bağımsız olarak daha yüksek getiri elde etmek isterler (Aydın, Başar ve Çoşkun, 2010: 298299).

Kurumsal yönetim mekanizmalarından, mülkiyet yapıs1; firmaların mülkiyet yapıs1, firmanın sermayesini temin edenlerin kim olduğunun ve sermaye paylarının büyüklügüunün belirlenmesini ifade etmektedir. Firmanın yönetimine, sermayenin önemli miktarına sahip olanlar yön vermektedirler. Firmaların mülkiyet yapıları, halka açık veya kapalı, kamu veya özel, yerli veya yabancı ve nihayet yönetsel veya kurumsal olarak sınıflandırılabilir. Mülkiyet yapısı kurumsal yönetim için önemli unsurlar içermektedir (İzciler, 2014: 16). Mülkiyet yapısında yoğunlaşma ifadesi ise, hisse senetlerinin çoğunluğuna sahip olan kişi sayısını göstermektedir. Başka bir ifade ile bir firmanın hisselerinin belirli kişilerin elinde toplanması ve bu kişilerin hisse oranlarının diğer kişilerin hisse oranlarına göre büyük olması, firma yönetiminin ve kontrolünün bu kişilere ait olması demektir. Bu bağlamda, yoğunlaşma ne kadar fazla ise, firmanın hâkim ortağı yönetime fazla risk almaması yönünde o oranda bask1 yapacaktır (Fettahoğlu ve Okuyan, 2009: 4-5).

Kontrol işletmenin faaliyetleri ile ilgili finansal politikalarının belirlenmesi sürecini etkileme gücü olarak ifade edilmektedir. Bu noktadan hareketle firma yönetimine katılma hakkı veren hisselerin çoğunluğunun bir/birkaç kişinin ya da grubun elinde bulunması ile pek çok yatırımcı arasında paylaşılmış olması yönetimin denetlenmesi ve etkin çalışmasının sağlanması bakımından önemlidir (Taşkın, Durak ve Aktaş, 2013). Bununla birlikte büyük hisselere sahip olan ortaklar firmayı kontrolleri altına almak isteyebilirler (Shleifer ve Vishny, 1986). Firmaların mülkiyet yapısı ile kontrol arasında doğrusal bir ilişki vardır. Başka bir ifade ile sermaye yoğunlaşması arttıkça hissedarın işletmede kontrolü artmaktadır. Hâkim hissedarlar belirli bir kişi olabileceği gibi aile, kurumsal yatırımcı veya yabancı sahipliği olabilmektedir.

Herhangi bir işletmede mülkiyet ve kontrol çok az durumlarda tam anlamıyla ayrışmıştır. Genellikle kontrol edenler, kontrol ettikleri firmalarda bir kısım öz sermayeye sahiptirler. Bazı sahipler ise öz sermaye pozisyonlarının büyüklüğünün neticesi olarak sahip 
oldukları firmalar üzerinde kontrolün bir bölümünü ellerinde tutarlar. Dolayısıyla mülkiyet yapısı kurumsal yönetimin potansiyel olarak önemli bir öğesidir (Kıyılar ve Belen, 2005: 21).

İşletmelerin finansman kararları bir çok faktörden etkilenmektedir. Örneğin aile işletmesi olması, yöneticilerin işletme sahibi veya hakim ortak olması, en büyük ortağın sermaye payı ve halka açıklık oranı işletmelerin sermaye yapısını etkilemektedir. Mülkiyet yapısı dışında işletmenin karlılığının istikrarlı olması ve firmanın büyüklüğü finansman kararları üzerinde etkilidir.

$\mathrm{Bu}$ çalışmanın amacı mülkiyet yapısının finansman kararları üzerindeki etkisini tespit etmektir. Araştırmada 2005-2012 yılları arasında Borsa İstanbul (BİST) imalat sanayide hisse senetleri işlem gören 136 firmanın verilerinden yararlanılmıştır. Ampirik analizlerde White periyot standart hataları ve kovaryans katsayısı yönteminden yararlanılmıştır.

$\mathrm{Bu}$ çalışma beş bölümden oluşmaktadır. Girişten sonra ikinci bölümde mülkiyet yapısının finansman kararları üzerindeki etkisini inceleyen çalışmalar özetlenmiştir. Üçüncü bölümde çalışmanın amacı, örneklemi, veri seti, bağımlı ve bağımsız değişkenler tanıtılarak, hipotezler geliştirilmiştir. Dördüncü bölümde ekonometrik bulgulara yer verilmiştir. Son bölümde ise araştırmanın genel bir değerlendirilmesi yapılarak önerilerde bulunulmuştur.

\section{LITERATÜR TARAMASI}

Firmaların mülkiyet yapısının etkisi literatürde 2 farklı açıdan araştırılmıştır. Birincisi; mülkiyet yapısı ile firma performansı arasındaki ilişkiyi inceleyen araştırmalardır ve bu konuda çok sayıda çalışma mevcuttur. İkincisi ise; mülkiyet yapısının sermaye yapısı üzerindeki etkisini inceleyen çalışmalardır. Mülkiyet yapısı ile sermaye yapısı arasındaki araştırmalar ise mülkiyet yoğunlaşması, yönetici sahipliği ve yabancı sahipliği şeklinde incelenmiş ve bu araştırmaların sayısı oldukça azdır. Bu bölümde bu araştırmanın amacı ile tutarlı bir şekilde mülkiyet yoğunlaşmasının sermaye yapısı üzerindeki etkisini inceleyen araştırmalar özetlenecektir.

Brailsford, Oliver ve Pua (2002) Avustralya firmaları açısından mülkiyet yapısı ile sermaye yapısı arasındaki ilişkiyi ampirik olarak test etmişlerdir. Yapılan analizler sonucunda büyük hissedar ile (sermaye payı en büyük olan 5 ortağın sermaye payının, toplam sermayeye oranı) kaldıraç oranı arasında pozitif bir ilişki bulmuşlardır. Buna karşın Short, Keasey ve Duxbury (2002) İngiltere firmalarına yaptığı çalışmalarında büyük hissedarlar (blockholders) ile kaldıraç oranı arasında negatif bir ilişkinin varlığını ortaya koymuşlardır. Başka bir ifade ile büyük hissedarların varlığı borç ve öz kaynağın temsilcilik maliyetlerini etkilediğini ileri sürmüşlerdir.

Driffield, Muhambre ve Pal (2007) Uzak Doğu ülke firmaları açısından mülkiyet yapısının sermaye yapısı üzerindeki etkisini incelemişleridir. Çalışma sonucunda, mülkiyet yoğunlaşması arttıkça kaldıraç oranının da arttığını belirlemişlerdir. Benzer şekilde King ve 
Santor (2008) 1998-2005 yılları için 613 Kanda firması üzerine yaptığı çalışmasında sermaye yoğunlaşması ile kaldıraç oranı arasında pozitif bir ilişki bulmuşlardır.

Li, Yue ve Zhao (2009) ise Çin'de faaliyette bulunan firmaların mülkiyet yapısının sermaye yapısı kararları üzerindeki etkisini incelemişlerdir. Araştırma sonucunda mülkiyet yapısının kaldıraç oranı üzerinde etkili olduğunu tespit etmişlerdir. Benzer sonuçlar Margaritis ve Psillaki (2010) tarafından da tespit edilmiştir.

Ellul (2011) ise 38 farklı ülkede 1992-2006 yılları arasında faaliyette bulunan 5975 firma üzerine yaptığı araştırma sonucunda sermaye yoğunlaşması ile kaldıraç oranı arasında pozitif bir ilişki elde etmiştir. Buna karşın Agrawal ve Nasser (2011) büyük hissedar olan bağımsız yönetim kurulu ile kaldıraç oranı arasında istatistiksel olarak anlamlı olmayan bir ilişki bulmuşlardır. Benzer sonuçlar Mehran, Taggart ve Yermack (1999) tarafindan da belirlenmiştir.

Michaely ve Vincent (2012) ABD firmaları üzerine yaptıkları araştırmalarında kurumsal yatırımcı sahipliğinin kaldıraç oranını negatif yönde etkilediğini tespit etmişlerdir. Benzer şekilde Sayman (2012) BİST firmaları açından mülkiyet yapısı ile sermaye yapısı arasındaki ilişkiyi araştırmıştır. Çalışma sonucunda halka açıklık oranı ile kaldıraç oranı arasında negatif bir ilişki bulmuştur.

Santos, Moreira ve Vieira (2014) 2002-2006 y1lları arasında 12 Bat1 Avrupa ülkesinden 694 firma ile mülkiyet yoğunlaşmasının sermaye yapısı üzerindeki etkisini araştırmışlardır. Geliştirilen dirençli regresyon modelleri sonucunda büyük hissedarlar ile kaldıraç oranı arasında negatif ve istatistiksel olarak oldukça anlamlı ilişkiler belirlemişlerdir.

\section{METODOLOJI}

Araştırmanın bu bölümünde veri seti, değişkenler tanıtılarak, literatürle tutarlı bir şekilde hipotezler geliştirilmiştir.

\subsection{Araştırmanın Amacı ve Veri Seti}

Bu çalışmanın amacı mülkiyet yapısının finansman kararları üzerindeki etkisini tespit etmektir. Başka bir ifade ile mülkiyet yapısının sermaye yapısını nasıl ve ne yönde etkilediği incelenecektir. Araştırmada şu sorulara cevap aranacaktır:

- $\quad$ Mülkiyet yoğunlaşması sermaye yapısını etkiler mi?

- Halka açıklık oranı sermaye yapısını etkiler mi?

- $\quad$ Firma büyüklüğü ve Varlık Karlılığı sermaye yapısını etkiler mi?

Araştırmada 2005-2012 yılları arasında BİST imalat sanayide hisse senetleri işlem gören 136 firmanın verilerinden yararlanılmıştır. Analiz kapsamında incelenen firmalara ait finansal veriler iki farklı yolla elde edilmiştir. İmalat sanayi firmalarının 2008 yılı ve öncesine ait dönemlere ilişkin finansal veriler Borsa İstanbul (BİST)'in resmi internet sayfasından (www.borsaistanbul.com), 2009 yılı ve sonrasına ait dönemlere ilişkin finansal veriler ise Kamuyu Aydınlatma Platformu (KAP)'ın resmi internet sayfasından (www.kap.gov.tr) temin 
edilmiştir. Mülkiyet yapısına ilişkin bilgiler ise 2005-2008 yılları için şirket yıllıklarından, 2009-2012 yılları için ise şirketlerin faaliyet raporlarından, web sayfalarından, dipnot bilgilerinden ve KAP'tan ulaşılmıştır.

\subsection{Araştırmada Kullanılan Değişkenler ve Hipotezler}

$\mathrm{Bu}$ araştırmanın bağımlı değişkeni kaldıraç (BORC) oranıdır. Bağımsız değişkenler ise en büyük ortağın sermaye payı (BUYUK1), en büyük ikinci ortağın sermaye payı (BUYUK2), halka açıklık oranı (HAO), toplam varlıklar (VARLIK) ve varlık karlılı̆̆ıdır (VKAR)'dır. Söz konusu bağımlı ve bağımsız değişkenler aşağıda tanıtılmıştır.

BORC: Firmaların toplam borçlarının toplam varlıklarına oranlanmasiyla elde edilmiştir. $\mathrm{Bu}$ oran; firmaların finansman kararlarını yani sermaye yapısı tespit etmek amacıyla bağımlı değişken olarak kullanılmıştır. BORC; varlıkların yüzde kaçının borçlarla finanse edildiğini göstermektedir. Toplam borç oranı yüksek olan işletmelerin faaliyetlerini devam ettirebilmesi borçlara bağlıdır. $\mathrm{Bu}$ oranın çok yüksek olması firmanın riskliliğinin artmasına ve mali sıkıntıya düşmesine hatta iflas etmesine neden olabilir. Özellikle kredi verenler açısından bu oranın düşük olması istenir (Elitaş ve Doğan, 2013: 46).

BUYUK1: Sermaye payı en büyük olan ortağın sermaye payının, toplam sermayeye bölünmesiyle elde edilmiştir.

BUYUK2: Sermaye payı en büyük ikinci ortağın sermaye payının, toplam sermayeye oranlanmasıyla hesaplanmıştır. En büyük veya en büyük ikinci sermaye payını elinde bulunduran hissedar işletmenin alacağı kararlarda söz sahibidir. Başka bir ifade ile yönetimin alacağı kararlarda etkin bir rol üstlenebilir. Bununla birlikte büyük hissedarlar işletmenin pazarlama satış, üretim, dağıtım politikaları, yatırım kararları, finansman ve temettü politikaları ile alınacak kararlarda da doğrudan etkilidir. Azınlık ortaklar ile kontrol gücünü ellerinde bulunduran ortaklar arasında bir temsilcilik sorunu ortaya çıkması kaçınılmazdır (La Porta, Lopez-De-Silanes ve Shleifer, 1999). Hisse senedi sahipleri içinde kontrol gücünü ellerinde bulunduran ortaklar işletmenin nakit akımları üzerinde daha fazla etkili olabilmektedir. İşletmenin sermayesine önemli oranda sahip olan ortaklar işletmedeki kontrol güçlerini; oy kullanmada imtiyaz sağlayan hisse senetleri ve holdingleşme yoluyla arttırmaktadırlar. Birinci en büyük ortak sadece yatırım amaçlı değil, direk işletmeyi yönetme maksadıyla da işletmelere ortak olabilmektedir (Sayman, 2012: 113). Ayrıca sermaye payı en büyük olan ortak yönetim kararlarında etkili olabilmesinden dolayı bağımsız değişken olarak çalışmaya dâhil edilmiştir. Mülkiyet yapısında ikinci sırada bulunan küçük ortağın mülkiyet yapısı unsuru olduğu için yine modele ilave edilmiştir.

Brailsford vd. (2002) göre firmaların mülkiyet yoğunluğundaki artışla birlikte, yabancı kaynak kullanım oranı da artmaktadır. Artan mülkiyet yoğunluğuna paralel olarak hisse senetlerinin büyük çoğunluğunu elinde bulunduran hissedarlar, firma yöneticilerini denetlemek için daha fazla gözetim çabası verecek ve bu durum da işletmenin yöneticilerin çıkarları doğrultusunda yönetilmesi ihtimalini azaltacaktır. Başka bir ifade ile mülkiyet 
yapısının dar olduğu durumlarda, büyük ortakların bunu korumak için borçlanmaya dayalı büyüme stratejisi benimsemektedirler (Sayman, 2012).

\section{$\mathrm{H}_{1}$ : En büyük ortağın sermaye payı finansman kararlarını etkilemektedir.}

$\mathrm{H}_{2}$ : En büyük ikinci ortağın sermaye payı finansman kararlarını etkilemektedir.

HAO: Firmaların halka açıklık yüzdesidir. Firmalar belirli oranlarda halka açılma yoluna giderek, sermaye edinimi, mülkiyetin tabana yayılması ve riskin dağıtılması gibi halka açılmanın olası avantajlarından faydalanmak istemektedirler. Halka açılma yoluyla mülkiyetin tabana yayılması aslında çok sayıda insanın firma hissesini alarak, firmanın ortağı olması işleminden başka bir şey değildir. Ancak bu durum, firmalara çeşitli açılardan avantajlar sağlarken, bu oluşan yapının profesyonel yöneticilere olan ihtiyacı zorunlu hale getirdiği görülmektedir (Büyükdereli, 2007: 26). Halka açıklık oranı firmaların sermaye yapısını etkilemektedir. Yönetimi kaybetme endişesinde bulunan işletme ortakları halka açıklık oranını belli seviyede tutmak ister. Halka açılmaları durumunda hisse senedi satışında eski ortaklara öncelik hakkı (Rüçhan Hakkı) tanımaktadırlar. Halka açıklık oranları yüksek olan işletmelerin sermaye yoğunlukları düşük, halka açıklık oranları düşük olan işletmelerin sermaye yoğunlukları da yüksek olmaktadır (Sayman, 2012: 215). Dolayısıyla firmaların halka açıklık yüzdesi sermaye yapısını etkileyebileceği için modele ilave edilmiştir.

\section{$\mathrm{H}_{3}$ : Halka açıklık oranı finansman kararlarını etkilemektedir.}

VARLIK: Firmaların toplam varlıklarıdır. Diğer değişkenler ile uyumlu olması için logaritması alınarak modele dâhil edilmiştir. Finans literatüründe toplam varlıklar firma büyüklük göstergesi ve kontrol değişken olarak kullanılmıştır.

Büyük firmalar için sermaye piyasalarındaki bilgi asimetrisi düşük olabilir. Bu sebeple büyük firmalar öz sermayeyi daha çok kullanarak, borç seviyesini düşük tutmaktadırlar (Rajan ve Zingales, 1995). Küçük firmalarda, firma yöneticileri ile sermaye piyasaları arasındaki bilgi asimetrisi daha fazladır (Harris ve Raviv, 1991). Bir firma büyüdükçe, daha fazla bilgi beklentisi oluşarak firmanın borçlanması kolaylaşır. Küçük firmalarda bilgi asimetrisi büyük firmalara göre daha fazladır. Bu durum, küçük firmaların dış kaynak kullanımlarını bilgi asimetrisi sebebiyle daha çok maliyetli hale getirir (Padron vd., 2005). Başka bir ifade ile daha büyük firmalar, daha küçük firmalara göre daha kolay ve daha düşük maliyetle borçlanma imkânına sahip olabilirler. Mülkiyet yoğunlaşmasının sermaye yapısı üzerindeki etkisini inceleyen Ruan, Tian ve Ma (2011); Wahba (2014) gibi yazarlar toplam varlıkları kontrol değişken olarak kullanmışlardır.

\section{$\mathrm{H}_{4}$ : Firma büyüklüğ̈̈ finansman kararlarını etkilemektedir.}

VKAR: Dönem net kârının toplam varlıklara oranlanmasıyla hesaplanmıştır. Bu oran firmaların karlılığını ve yönetimin yeteneğini gösteren bir orandır. Bir firmanın finansman şekline veya sermaye yapısındaki değişikliklere göre $V K A R$ yüksek veya düşük olabilir. Büyük ölçüde yabancı kaynak kullanan, dolayısıyla ağır bir borç yükü altında bulunan firmaların varlık karlılığı, varlıklarının önemli bir bölümünü öz kaynakları ile finanse eden 
firmalara kıyasla daha düşük olması normaldir. Dolayısıyla firmanın finansman şekline göre farklı sonuçlar veren, pay ve paydası arasında tutarlılık bulunmayan bu oranı, bir firmanın kârlılık durumunun değerlendirilmesinde bir ölçü olarak kullanırken, dikkatli olmak gerekir (Akgüç, 1998: 70). Barton, Hill ve Sundaram (1989); Mehran, Taggart ve Yermack (1999); Margaritis ve Psillaki (2010); Ruan, Tian ve Ma (2011) gibi yazarlar da benzer çalışmalarda kontrol değişken olarak kullanmışlardır.

Yüksek kaldıraçlı firmalar riskli olmakla birlikte, bu firmaların borçlarını geri ödemesi ve yeni krediler temin etmesi her zaman mümkün olmayacaktır. Yüksek kaldıraç genellikle olumsuz bir durum olmakla birlikte, borç yatırım ilişkisi, firmaların karlılığını olumlu yönde etkileyebilir (Doğan, 2013: 127). Ayrıca firmaların karlılıklarının istikrarlı olması son derece önemlidir. Karlılığ kullanabilirler.

\section{$\mathrm{H}_{5}$ : Varlık Karlılığı finansman kararlarını etkilemektedir.}

\subsection{Araştırmanın Yöntemi}

Araştırmada 2005-2012 yıllarına ait 136 firmanın 8 yıllık verisinden yararlanılmıştır. $\mathrm{Bu}$ periyotta BİST İmalat sanayide işlem gören tüm firmalar analize dahil edilmesinden dolayı; veri seti dengeli panel veri özelliği taşımaktadır. Araştırmada veriler Eviews 7 programından yararlanılmıştır. Değişkenler arasında ekonometrik olarak anlamlı ilişkiler elde edilebilmesi için serilerin durağan olması gerekmektedir. Değişkenlere ait zaman serilerinde trend bulunuyorsa, ilişki gerçek olmaktan çok sahte regresyon (düzmece) olmaktadır. $\mathrm{Bu}$ yüzden regresyon modelin gerçek bir ilişkiyi mi yoksa yanıltıcı bir ilişkiyi mi gösterdiği zaman serisi verilerin durağan olup olmamalarıla ilgilidir (Sevinç, 2013: 235-236). Araştırmada Fisher ADF Kök Testi ile serilerin durağan olup olmadığı araştırılmıştır. Test sonuçlarında serilerin durağan olduğunu yani birim köke sahip olmadıkları anlaşılmıştır. Daha sonra araştırmada birim etkilerinin sabit mi yoksa tesadüfi mi olduğuna karar vermek için Hausman testi kullanılmıştır. Hausman testi sonuçları tespit edilen olasılık değeri 0,05 'ten küçük olmasından dolayı sabit etkiler modelinin tercih edilmesinin daha doğru sonuçlar vereceğini göstermektedir.

Regresyon modelinin tahmininde çoklu varyans sorunu (heteroskedasite), otokorelasyon ve birimler arası korelasyon olması durumunda hata terimin varyansı birim matrise eşit olmamaktadır. Bu durum modelin tutarsızlığına sebep olmakta ve etkinliğini etkilemektedir. $\mathrm{Bu}$ nedenlerden dolayı modelde heteroskedasite, otokorelasyon ve birimler arasında korelasyondan en az birisi olması durumunda ya parametre tahminlerine dokunmadan standart hatalar düzetilmeli (dirençli standart hatalar elde edilmeli) ya da varlıkları halinde uygun yöntemler ile tahmin edilmesi gerekir (Tatoğlu, 2013: 242). Bu çalışmada söz konusu problemler olmasından dolayı sabit etkiler modeli ile White periyot standart hataları ve kovaryans katsayısı yöntemi kullanılarak hatalar düzeltilmiştir. Böylece geliştirilen model söz konusu hatalara karşı dirençli hale gelmiştir. 


\section{AMPÍRIKK BULGULAR}

Tablo 1'de ampirik analizlerde kullanılan bağımlı ve bağımsız değişkenler ile ilgili tanımlayıcı istatistik sonuçları gösterilmiştir.

Tablo 1: Tanımlayıcı İstatistikler

\begin{tabular}{|l|c|c|c|c|c|c|}
\hline & BORC & BUYUK1 & BUYUK2 & HAO & VARLIK & VKAR \\
\hline Gözlem Sayısı & 1088 & 1088 & 1088 & 1088 & 1088 & 1088 \\
\hline Ortalama &, 459 & 49,2619 & 10,4326 & 32,90 & 19,2150 &, 0199 \\
\hline Medyan &, 437 & 49,2900 & 6,8850 & 29,96 & 19,1475 &, 030 \\
\hline Std. Sapma &, 232 & 22,73167 & 11,68556 & 19,34 & 1,46110 &, 188 \\
\hline Çarpıklık &, 222 &, 103 & 1,122 & 1,01 &, 428 & $-12,62$ \\
\hline Çarpıklık Std. Ht. &, 074 &, 074 &, 074 &, 074 &, 074 &, 074 \\
\hline Basıklık &,- 811 &,- 697 &, 543 & 1,82 &, 015 & 293,77 \\
\hline Basıklık Std. Ht. &, 148 &, 148 &, 148 &, 148 &, 148 &, 148 \\
\hline Minumum &, 01 &, 59 &, 00 &, 54 & 15,65 & $-4,45$ \\
\hline Maxmimum & 1,00 & 97,54 & 43,73 & 0,99 & 23,56 & 1,01 \\
\hline
\end{tabular}

Tablo 1 incelendiğinde en büyük ortağın ve en büyük ikinci ortağın sermaye payı incelendiğinde oranın \%49,26 ve \%10,43 olduğu görülmektedir. Chen (2012) mülkiyet yapıs1 ile firma performansı arasındaki ilişkiyi incelediği çalışmasında en büyük birinci ortağın sermaye payını Norveç için \%28,6 Danimarka için \%23,9 Finlandiya için \%20,3 ve İsveç için $\% 22,9$ olarak hesaplamıştır. İskandinav ülkelerinden BİST firmaların en büyük ortağın sermaye payı oldukça fazladır. Bu durum BİST firmalarının büyük bir kısmının aile şirketlerinden oluşması, sermayenin belli bir kesimde, aile içinde ve yönetim kurulunda toplanması ile açıklanabilir. Bu sonuçları paralel bir şekilde ortalama halka açıklık oranı (HAO) \%32,90'dır. Gao, (2002) 2001 y1lı için HAO'nı ABD’de \%93,9; gelişmiş ülkelerde HAO'nın ortalamasını \%86,4 ve gelişmekte olan ülkelerde HAO'nın ortalamasını \%77,5 olarak hesaplamıştır. Avrupa'daki ortalama halka açıklık oranı \%36,93 iken, bu oran Fransa'da \%14'tür (Ginglinger ve Hamon, 2007). Gelişmiş ülkelerde, az gelişmiş ülkelere göre sermayenin daha fazla tabana yayıldığı görülmektedir. Türkiye'de ise halka açıklık oranının söz konusu diğer ülkelerden daha azdır. Bu durum yine Türkiye'deki işletmelerin aile şirketlerinden oluşması, sermayenin ve kontrolün belli bir kesimde toplanması ile açıklanabilir.

Tablo 2: Mülkiyet Yapısı ile Kaldıraç Oranı Arasındaki İlişki

\begin{tabular}{|l|c|c|c|c|c|c|}
\hline & BORC & BUYUK1 & BUYUK2 & HAO & VARLIK & VKAR \\
\hline BORC & 1 & & & & & \\
\hline BUYUK1 &, $101^{*}$ & 1 & & & & \\
\hline BUYUK2 &, 058 &,- 059 & 1 & & & \\
\hline HAO &,- 041 &, $512^{* *}$ &,$- 081^{* *}$ & 1 & & \\
\hline VARLIK &, $084^{*}$ &,- 009 &, $134^{* *}$ &,- 037 & 1 & \\
\hline VKAR &,$- 363^{* *}$ &, 016 &, 002 &,$- 101^{* *}$ &, $288^{* *}$ & 1 \\
\hline
\end{tabular}


Tablo 2'de mülkiyet yapısı ile kaldıraç oranı arasındaki ilişkiyi gösteren korelasyon analizi sonuçları yer almaktadır. Korelasyon sonuçları incelendiğinde BUYUK1 ile kaldıraç oranı (BORC) arasında pozitif ve istatistiksel olarak anlamlı bir ilişki olduğu görülmektedir. Başka bir ifade ile en büyük ortağın sermaye payı (BUYUK1) arttıkça kaldıraç oranı \%10,1 artmaktadır. Bununla birlikte kaldıraç oranı ile varlıklar (VARLIK) arasında pozitif, varlık karlılığ1 (VKAR) arasında negatif bir ilişki vardır. HAO ve BUYUK2 ile BORC arasında istatistiksel olarak anlamlı olmayan bir ilişki vardır.

Tablo 3: White Periyot Standart Hataları ve Kovaryans Katsayısı Yöntemi Sonuçları

\begin{tabular}{|c|c|c|c|c|}
\hline Değişkenler & Etkinlik & Std. Hata & T-istatistiği & P Değeri \\
\hline SABİT & -1.398587 & 0.633934 & -2.206203 & 0.0276 \\
\hline BUYUK1 & 0.001272 & 0.000717 & 1.774978 & 0.0762 \\
\hline BUYUK2 & 0.001081 & 0.001535 & 0.704087 & 0.4816 \\
\hline HAO & -0.001076 & 0.000707 & -1.522613 & 0.1282 \\
\hline VARLIK & 0.091167 & 0.032761 & 2.782820 & 0.0055 \\
\hline VKAR & -0.145514 & 0.061767 & -2.355845 & 0.0187 \\
\hline F İstatistiği & \multicolumn{4}{|c|}{32.15395} \\
\hline F İst. Olasılığg & \multicolumn{4}{|c|}{0.0000} \\
\hline Durbin-Watson & \multicolumn{4}{|c|}{1.61252} \\
\hline$\overline{\mathbf{R}^{2}}$ & \multicolumn{4}{|c|}{0.834117} \\
\hline Düz. $\mathbf{R}^{2}$ & \multicolumn{4}{|c|}{0.808175} \\
\hline
\end{tabular}

Tablo 3'te sabit etkiler modeli ile White periyot standart hataları ve kovaryans katsayısı yöntemi sonuçları gösterilmiştir. Modelde $\mathrm{F}$ istatistik düzeyinin istatistiksel olarak anlamlı olduğu ve modelin yeterli açıklama gücüne sahip olduğu görülmektedir. Bununla birlikte kaldıraç oranındaki (BORC) değişimin yaklaşık \%80'lik kısmı BUYUK1, BUYUK2, HAO, VARLIK ve VKAR ile açıklanmaktadır. Başka bir ifade ile regresyon modelinin göreceli etkinliğini tespit etmede kullanılan "belirleme katsayısı"nın $\left(\mathrm{R}^{2}\right) \% 80$ olduğu anlaşılmaktadır. Ayrıca Tablo 3'te en büyük ortağın sermaye payı (BUYUK1), firma büyüklüğü (VARLIK), varlık karlılığ 1 (VKAR) değişkenlerinin BİST firmalarının finansman kararları üzerinde etkili olduğu görülmektedir.

Modelin sonuçları incelendiğinde en büyük ortağın sermaye payı (BUYUK1) ile kaldıraç oranı arasında pozitif ve istatistiksel olarak \%10 düzeyinde anlamlı bir ilişsi vardır. Başka bir ifade ile en büyük ortağın sermaye payı arttıkça kaldıraç oranı da artmakta ve $\mathrm{H}_{1}$ hipotezi kabul edilmektedir. En büyük ikinci ortağın sermaye payı (BUYUK2) ve halka açıklık oranı (HAO) ile kaldıraç oranı arasında istatistiksel anlamlı bir ilişki yoktur. HAO ile kaldıraç oranı ilişki anlamlı olmasa da, bu ilişkinin negatif $(\mathrm{p}=0,1282)$ olması önemli bir sonuç olarak değerlendirilebilir. En büyük ortağın sermaye payı ile kaldıraç oranı arasındaki pozitif ilişkiyi destekler nitelikte mülkiyet yapısının dar olduğu durumlarda, borçlanmaya dayalı büyüme tercih edildiğini göstermektedir. Sonuç olarak $\mathrm{H}_{2}$ ve $\mathrm{H}_{3}$ hipotezleri reddedilmektedir. Kontrol değişkenler incelendiğinde kaldıraç oranı ile varlıklar arasında 
istatistiksel olarak \%1 düzeyinde pozitif bir ilişki, VKAR arasında ise negatif bir ilişki vardır. Yani; karlılığın azalması kaldıraç oranını yükseltirken, firma büyüklüğü kaldıraç oranını azaltmaktadır. $\mathrm{H}_{4}$ ve $\mathrm{H}_{5}$ hipotezleri reddedilmektedir.

\section{SONUÇ}

$\mathrm{Bu}$ araştırmada mülkiyet yapısının finansman kararları üzerindeki etkisi incelenmiştir. Araştırmada 2005-2012 yılları arasında Borsa İstanbul (BİST) imalat sanayide hisse senetleri işlem gören 136 firmanın verilerinden yararlanılmıştır. Araştırmada kullanılan veriler dengeli panel veri özelliği taşımaktadır. Ampirik analizlerde White periyot standart hataları ve kovaryans katsayısı yönteminden yararlanılmıştır.

Analiz sonuçları incelendiğinde en büyük ortağın sermaye payı ile kaldıraç oranı arasında pozitif ve istatistiksel olarak anlamlı bir ilişki vardır. Başka bir ifade ile mülkiyet yoğunluğu veya hakim ortağın sermaye yapı arttıkça kaldıraç oranı da artmaktadır. Bu durum; mülkiyet yapısının az veya hissedar sayısının az olduğu durumlarda, büyük hissedarların, bu durumu muhafaza etmek amacıyla borçlanmaya dayalı büyüme stratejisi benimsemeleri ile açıklanabilir. Sermaye yoğunluğu artmasıyla birlikte firmalarda kontrol de artmaktadır. BİST firmaları açısından kontrol artmasıyla birlikte, öz sermaye ile büyümek yerine yabancı kaynaklarla büyüme tercih edildiği görülmektedir. Bununla birlikte büyük hissedarlar, şirket içi denetim gücüne ve güdüye sahip olmalarından dolayı kendi çıkarlarını maksimize etmeye çalışabilirler. Ayrıca büyük hisselere sahip olan ortaklar işletmeyi kontrolleri altına almak isteyebilirler. $\mathrm{Bu}$ durum neticesinde büyük hissedara sahip olan işletmenin temsil maliyetlerinde bir azalma gösterebilir. Tüm bunların dışında büyük hissedarlar işletme içerisinde neler olduğunu gözlemleyip izleme ve müdahale etme olanağı da tanıyabilir.

Mülkiyet yapısı ile sermaye yapısı arasındaki ilişkiyi ölçen çalışmalar incelendiğinde Brailsford, Oliver ve Pua (2002); Driffield, Muhambre ve Pal (2007); King ve Santor (2008); Margaritis ve Psillaki (2010); Ellul (2011); Agrawal ve Nasser (2011) ile aynı yönde sonuçlar elde edilirken Mehran, Taggart ve Yermack (1999); Short, Keasey ve Duxbury (2002); Michaely ve Vincent (2012); Santos, Moreira ve Vieira (2014) ile zıt yönde sonuçlar tespit edilmiştir.

Kontrol değişkenler incelendiğinde sermaye yapısı ile toplam varlıklar arasında pozitif bir ilişki vardır. Başka bir ifade ile firma büyüklüğünün artması ile birlikte kaldıraç oranı da artmaktadır. Bir firma büyüdükçe, hakkında daha fazla bilgi beklentisi oluşarak pazardaki bilgi asimetrisi düzeyini azaltıp, borçlanmayı kolaylaştırmaktadır. Büyük firmalar, nispeten daha küçük firmalara göre daha kolay ve maliyeti daha düşük bir şekilde borçlanabilirler. $\mathrm{Bu}$ durum; büyük firmalar kaldıraç etkisinden daha fazla yararlandıklarını göstermektedir.

Diğer değişken olan Varlık Karlılığı ile sermaye yapısı arasında negatif bir ilişki vardır. Yani; varlık başına düşen karlılığın azalması kaldıraç oranı yükseltmektedir. BİST’te 
işlem gören firmaların kaldıraç oranının yükselmesi kaynak maliyetini artırmakta, dolayısıyla da firma karlılığının azalmasına neden olmaktadır.

Mülkiyet yapısının finansman kararları üzerindeki etkisini inceleyen bu araştırmanın bazı kısıtları bulunmaktadır. Araştırmanın bulguları; Borsa İstanbul'da imalat sanayide 20052012 yılları arasında faaliyette bulunan firmalar açısından geçerlidir. Gelecek çalışmalarda farklı sektörler veya imalat sanayide bulunan alt sektörler açısından benzer çalışmalar yapilabilir.

\section{KAYNAKLAR}

Agrawal, A. - Nasser, T., (2011), Corporate Financial and Investment Policies in the Presence of a Blockholder on the Board, http://papers.ssrn.com/sol3/papers.cfm?abstract_id=1783891 (01.10.2015).

Akgüç, Ö., (1998), “Finansal Yönetim”, Avcıl Basım Yayın Dağıtım, İstanbul.

Aydın, N., Başar M. - Çoşkun M., (2010), “Finansal Yönetim”, Detay Yayıncılık, Ankara.

Barton, S. L., Hill, N. C. - Sundaram, S., (1989), “An Empirical Test of Stakeholder Theory Predictions of Capital Structure”, Financial Management, 18(1), pp.36-44.

Brailsford, T. J., Oliver, B. R. - Pua, S. L. H., (2002), “On the Relation Between Ownership Structure and Capital Structure”, Journal of Accounting and Finance, Vol: 42, pp.1-26.

Büyükdereli, M., (2007), “İMKB’de Faaliyet Gösteren Reel Sektör Firmalarının Mülkiyet Yapısının, Bu Firmaların Finansal Performansları Üzerine Etkisi”, Marmara Üniversitesi, Sosyal Bilimler Enstitüsü, Yüksek Lisans Tezi, İstanbul

Chen, L., (2012), “The Effect of Ownership Structure on Firm Performance: Evidence from Non-financial Listed Companies in Scandinavia”, Aarhus University, Msc in Finance \& International Business, Aarhus School of Business.

Driffield, S.N., Mahambre, V. - Pal, S., (2007), "How Does Ownership Affect Capital Structure and Firm Value? Recent Evidence from East Asia”, Centre for Economic Development \& Institutions Brunel University West London, Working Paper, http://papers.ssrn.com/sol3/papers.cfm?abstract_id=998361 (01.10.2015).

Doğan, M., (2013), “Sigorta Firmalarının Sermaye Yapısı İle Karlılık arasındaki İlişki: Türk Sermaye Piyasası Üzerine Bir İnceleme”, Muhasebe ve Finansman Dergisi, Sayı: 57, ss.121- 136.

Elitaş B. L. - Doğan M., (2013), "Sermaye Yapısını Belirleyen Faktörler: İMKB Sigorta Şirketleri Üzerine Bir Araştırma”, Muhasebe Bilim Dünyası Dergisi, 15(2), ss.41-57.

Ellul, A., (2011), “Control Motivations and Capital Structure Decisions” The Centre for Governance, Institutions and Organizations (CGIO) Academic Conference, August 25th and 26th, NUS Business School, Singapore. 
Ercan, M. K. - Ban, Ü., (2005), Değere Dayalı İşletme Finansı: Finansal Yönetim, Gazi Kitabevi, Ankara.

Fettahoğlu, A. - Okuyan, H. A., (2009), "İşletmelerde Sahiplik Yapısında Kaynak Bileşimi Üzerindeki Etkisi: İMKB’de Bir Uygulama”, Anadolu Uluslararası İktisat Kongresi, Eskişehir.

Gao, S., (2002), “China Stock Market in a Global Perspective. Research Report, Dow Jones Indexes, http://people.stern.nyu.edu/jmei/b40/ChinaIndexCom.pdf (20.01.2014).

Ginglinger, E., Hamon, J., (2007), “Ownership, Control and Market Liquidity. Finance International Meeting Paper,” http://www.europlacefinance.com/files/_financed_paper_1347.pdf (18.01.2014).

Harris, M. - Raviv, A., (1991), “The Theory of Capital Structure”, Journal of Finance, 46, pp.297- 355.

İzciler, D., (2014), “Kurumsal Yönetim İlkelerine Uyum Sürecinin Şirketlerin Performansları Üzerine Etkileri”, Marmara Üniversitesi, Sosyal Bilimler Enstitüsü, Yüksek Lisans Tezi, İstanbul .

Kıyılar, M. - Belen, M., (2005), "Kurumsal Yönetim Kavramı ve İlkeleri: Bir Kurumsal Yönetim Formu Olarak Türkiye'de Holding Yapılanma Biçimlerinin Değerlendirilmesi”, İSMMMO 1. Uluslararası Muhasebe Denetimi ve VII. Türkiye Muhasebe Denetimi Sempozyumu, Antalya, https://www.google.com.tr/?gfe_rd=cr\&ei=DrlYVuWIKM2v8weYmbaABQ\#q=Kuru msal+Y\%C3\%B6netim+Kavram\%C4\%B1+ve+\%C4\%B0lkeleri:+Bir+Kurumsal+Y\% C3\%B6netim+Formu+Olarak+T\%C3\%BCrkiye\%E2\%80\%99de+Holding+Yap\%C4\% B1lanma+Bi\%C3\%A7imlerinin+De\%C4\%9Ferlendirilmesi (01.10.2015).

King, M. R. - Santor, E., (2008), "Family Values: Ownership Structure, Performance and Capital Structure of Canadian Firms”, Journal of Banking \& Finance, 32, 2423-2432.

La Porta, R., Lopez-De-Silanes, F.- Shleifer, A., (1999), "Corporate Ownership Around the World”, Journal of Finance, 54, pp.471-517.

Li, K., Yue, H. - Zhao, L., (2009), Ownership, Institutions, and Capital Structure: Evidence from China”, Journal of Comparative Economics, 37(3), pp.471-490.

Margaritis, D. - Psillaki, M., (2010), "Capital Structure, Equity Ownership and Firm Performance”, Journal of Banking \& Finance, Vol: 34, pp.621-632.

Mehran, H., Taggart, R. A. - Yermack, D., (1999), “CEO Ownership, Leasing, and Debt Financing”, Financial Management, 28(2), pp.5-14.

Michaely, R. - Vincent, C., (2012), “Do Institutional Investors Influence Capital Structure Decisions”, SSRN working paper, https://www.google.com.tr/?gfe_rd=cr\&ei=6BkVs6ALeyv8weDjrLoBw\#q=Do+Institutional+Investors+Influence+Capital+Struct ure+Decisions (01.10.2015). 
Padron, Y., Aplinario, G., Santana, O. M., Martel, M. C. V. - Sales, L. J., (2005), "Determinants Factors of Leverage: An Emprical Analysis of Spanish Corporations", Journal of Risk Finance, 6 (1), pp.60- 68.

Rajan, R. G. - Zingales, L., (1995), "What Do We Know about Capital Structure? Some Evidence from International Data”, The Journal of Finance, 50 (5), pp. 1421- 1460.

Ruan W., Tian G. - Ma S., (2011), "Managerial Ownership, Capital Structure and Firm Value: Evidence from China’s Civilian-run Firms”, Australasian Accounting Business and Finance, 5(3), pp.73-92.

Santos, M. S., Moreira, A.C. - Vieira E. C., (2014), "Ownership Concentration, Contestability, Family Firms and Capital Structure”, Journal of Management \& Governance, 18(4), pp.1063-1107.

Sayman, Y., (2012), "Sahiplik Yapısının Firma Performansı Ve Sermaye Yapısı Üzerine Etkileri: İMKB'de İşlem Gören Üretim Firmalarında Bir Uygulama”, Ankara Üniversitesi, Sosyal Bilimler Enstitüsü, Doktora Tezi, Ankara.

Sevinç, V., (2013), “Türkiye'ye Gelen Yabancı Turist Sayısı, Amerikan Doları Kuru ve Ekonomik Kriz Yılları Arasında Bir Granger Nedensellik İlişkisi Analizi”, Ekonomik ve Sosyal Araştırmalar Dergisi, 9(2), ss.233- 249.

Shleifer, A. - Vishny, R. W., (1986), “Large Shareholders and Corporate Control”, Journal of Political Economy, 94(3), pp.461- 488.

Short, H., Keasey, K., - Duxbury, D., (2002), “Capital Structure, Management Ownership and Large External Shareholders: A UK Analysis”, International Journal of the Economics of Business, 9(3), pp.375-399.

Taşkın, F. D., Durak, M. G. - Aktaş, M., (2013), "Kurumsal Yönetim Uygulamalarının İşletme Performansı Üzerindeki Etkileri: Bist Şirketleri Üzerinde Bir Uygulama”, 17. Finans Sempozyumu/23-26 Ekim 2013/Muğla, http://efinans.co/wpcontent/uploads/2013/11/12-22.pdf, (25.01.2013)

Tatoğlu, F. Y., (2013), “İleri Panel Veri Analizi, Beta Yayınevi, İstanbul.

Wahba H., (2014), “Capital Structure, Managerial Ownership and Firm Performance: Evidence From Egypt”, Journal of Management \& Governance, Vol: 18, pp.10411061. 
